\title{
Creep and Shrinkage of Concrete in Eurocode 2 and Polish Bridge Standards-Necessity for Implementation
}

\author{
Janusz Hołowaty \\ Faculty of Civil Engineering and Architecture, West Pmeranian University of Technology, Szczecin PL-70-311, Poland
}

\begin{abstract}
Estimation of creep and shrinkage in concrete bridges is still approximate and uncertain. Over the years, Polish Codes for Concrete Structures partially adapted the CEB (Euro-International Concrete Committee)-FIP (International Federation for Prestressing) models used to predict creep and shrinkage of concrete. In the currently used Polish concrete bridge code, modified CEB-FIP 1970 recommendations are used. At the time the standard was implemented, it introduced simple methods for the evaluation of final creep coefficients and shrinkage strains. It was sufficient for simple bridge structures and concrete technology used at that times. As modern bridge structures have become increasingly complex with variable construction techniques and developing concrete technology, the implementation of Eurocode 2 is necessary as it gives more practical and accurate methods for the prediction of creep and shrinkage effects. A comparative analysis of the time-dependent deformation of concrete included in Eurocode 2 and in Polish Bridge Codes is pointing out that there is a necessity for more adequate criteria for the rapidly growing concrete bridge stock in Poland.
\end{abstract}

Key words: Concrete bridges, rheological parameters, creep, shrinkage.

\section{Introduction}

Time-dependent parameters of structural concrete such as creep and shrinkage make gradual changes in stresses and strains in reinforced and prestressed concrete structures. In some types of concrete structures, e.g., large bridges and structures constructed in stages, time-dependent stresses and deformations may be a few times higher than those which are instantaneous deformations at the time of loading. Many concrete models have been developed over time to describe the time-dependent behavior of structural concretes which have adapted the changing parameters of concrete mixes as well as contemporary used cements, additives and admixtures [1-10]. However, modelling for creep and shrinkage in concrete bridges is still approximate, due to the great number of both variable and uncertain parameters. Methods for time-dependent analysis given in the

Corresponding author: Janusz Hołowaty, Dr., associate professor, research fields: testing and design of bridges. E-mail: jah@wp.pl. literature and codes are sometimes too simplified, leading to misunderstandings in the real-time behavior of concrete structures [6, 11, 12]. Many variable parameters induce significant differences in the deformations estimated, and lead to serviceability problems if they are treated too crudely. As concrete is a continuously developing material, evolution in its properties should be expected with development of concrete technology.

Over the years, Polish Codes for Concrete Structures adapted the CEB (Euro-International Committee for Concrete)-FIP (International Federation Prestressing) prediction models in the creep and shrinkage of concrete [1, 13-15]. In the Polish Concrete Bridge Code PN-91/S-10042 [1], modified CEB-FIP 1970 recommendations are used. Eurocode 2 [2, 3] is based on a modified CEB-FIB Mode Code 1990 [4, 8, 11, 15-19]. At the time the Polish Bridge Standard was implemented, it was sufficient and introduced simple methods for the evaluation of final creep coefficients and shrinkage strains. At present, some bridge structures have 
become increasingly complex using modern execution techniques, i.e., cantilever, incremental launching or span-by-span construction. It requires more sophisticated methods of time-dependent analysis, taking into account the varying concrete properties along the length and the long-term distribution of forces and stresses [3, 8, 9, 20].

Methods for the evaluation of deformational parameters adapted in the Polish Bridge Code (PN-S-10042) for the designing of concrete structures and Eurocode 2 are presented. The progressively evolving CEB-FIP models and their implementation in Eurocode 2 now give a practical and accurate method for the prediction of creep and shrinkage effects. As more precise approach, it should be implemented for the rapidly growing bridge stock in Poland.

\section{Creep and Shrinkage of Concrete}

Concrete structures response to load is both immediate and time-dependent. Generally, at constant temperature, the total concrete strain at time $t, \varepsilon_{c}(t)$ is expressed as the sum of the instantaneous strain $\varepsilon_{c i}(t)$, creep strain $\varepsilon_{c c}(t)$ and shrinkage strain $\varepsilon_{c s}(t)$ :

$$
\varepsilon_{c}(t)=\varepsilon_{c i}(t)+\varepsilon_{c c}(t)+\varepsilon_{c s}(t)
$$

Final creep strain $\varepsilon_{c c}\left(\infty, t_{0}\right)$ of concrete at time $t=\infty$ due to the constant compressive stress of $\sigma_{c}$ applied at concrete age of $t_{0}$ is calculated as:

$$
\varepsilon_{c c}\left(\infty, t_{0}\right)=\varphi\left(\infty, t_{0}\right) \frac{\sigma_{c}}{E_{c}}
$$

where, $\varphi\left(\infty, t_{0}\right)$ is the final creep coefficient and $E_{c}$ is the tangent modulus. Creep coefficient is usually determined in codes as a function of several parameters such as ambient humidity, composition of the concrete mix and dimensions of member. When a structure requires more detailed time-dependent analyses, the total stress-produced strain is calculated using creep function $J\left(t, t_{0}\right)$.

Final shrinkage strain $\varepsilon_{c s, \infty}$ is subdivided into drying shrinkage $\varepsilon_{c d, \infty}$ which begins at the age of concrete $t_{\mathrm{s}}$ (the start of drying) and autogenous shrinkage $\varepsilon_{c a}(\infty)$ [2]:

$$
\varepsilon_{c s, \infty}=\varepsilon_{c d, \infty}+\varepsilon_{c a}(\infty)
$$

Drying shrinkage strain begins to develop when the concrete sets or at the end of moist curing at the age $t_{s}$. Shrinkage continues to increase with time at a decreasing rate reaching a final value. Drying shrinkage is affected by parameters which affect the drying of concrete. Autogenous shrinkage depends on the concrete strength and develops during the hardening of concrete. After load application, instantaneous (or elastic) strain appears, which is followed by additional gradually increased creep strain. For simplicity, the components of concrete strain are calculated separately and summed to obtain the total value. In reality, neither creep nor shrinkage ever appear alone, nor are the entirely reversible processes.

The estimation of creep and shrinkage in concrete requires the adaption of reliable prediction models which realistically describe the behavior of a concrete structure over time. Creep is produced by permanent load, while shrinkage is independent of loads. Creep and shrinkage may cause excessive deflection, deformation and problems with serviceability. Their influence is higher for prestressed than for reinforced concrete structures. Creep and shrinkage are responsible for losses in prestressed forces and the shortening of prestressed members. Assessment of creep and shrinkage is important in concrete's serviceability limit which is leading to the design of prestressed concrete elements. Restraint in shrinkage may result in cracking developing over time. Simplified methods for the determination of creep and shrinkage are useful in designing simple concrete structures where the influence of concrete deformability on resistance and service is of less importance. However, the design or verification of a structure vulnerable to time-dependent deformation requires the adaption of analysis which takes into account the change in strains over time.

The reliable prediction of time-dependent effects in concrete structures should take into account the 
variation of deformational parameters of concrete over time and the interdependence of creep and stress history. Shrinkage is non-uniform across sections and is restrained by reinforcement and other members or supports. Although shrinkage is independent of stress, restrained shrinkage may cause internal forces and deformations. The most appropriate way of determining the deformational parameters of concrete is by testing, and even short-term tests give reasonable guidance for long-term values [3].

For simple bridge structures, approximate and straightforward methods for the estimation of creep and shrinkage are quite satisfactory. For bridges susceptible to time effects in concrete and with complex technological construction, more precise procedures for time-dependent analysis should be used [2, 3, 8, 9, 11, 20].

The long-term behavior of concrete in the creep and shrinkage of plain ordinary concrete according to the Polish Bridge Standard PN-91/S-10042 [1] and Eurocode 2 [2] is presented in the next sections. Comparisons of creep coefficients and shrinkage strains are made for cylinder specimens of diameter $150 \mathrm{~mm}$ and height $300 \mathrm{~mm}$, i.e., of notional size $h_{0}=$ $75 \mathrm{~mm}$. Concrete mix parameters are taken for a typical recipe for $\mathrm{C} 25 / 30$ concrete of a normal class of cement (marked $\mathrm{N}$ in EC2 [2]) for inside conditions (RH (relative humidity) $=50 \%$ ) and outside conditions $(\mathrm{RH}=80 \%)$. Comparison of time-dependent deformations in the codes is limited to ordinary concrete. Such concrete has predominantly been used in concrete bridges in Poland since the 1980s when the concrete bridge standard PN-91/S-10052 was introduced.

\section{Creep and Shrinkage in the Polish Bridge Code (PN-S)}

In the Polish Bridge Standard, values of final creep coefficients $\varphi_{p}=\varphi\left(\infty, t_{0}\right)$ and final shrinkage strains $\varepsilon_{s 0}=\varepsilon_{c s, \infty}$ for ordinary concrete are given for typical technological conditions and normal maturity of concrete. The values are tabulated for the nominal size of the member $h_{0}=150 \mathrm{~mm}$ and $600 \mathrm{~mm}, \mathrm{RH}=50 \%$ and $80 \%$ and age at the time of loading $t_{0}=7,28$ and 90 days. For indirect values, interpolation is used. The final creep strain $\varepsilon_{c c}\left(\infty, t_{0}\right)$ is calculated using Eq. (2). In cases where the influence of the concrete mixture or limited time $t$ must be taken into account, the coefficients $k_{b}$ and $k_{t}$ are used, respectively. Coefficient $k_{b}$ is described by the $w / c$ (water/cement) ratio and cement content $c\left(\mathrm{~kg} / \mathrm{m}^{3}\right)$. Coefficient $k_{t}$ describes the dependence of creep or shrinkage versus the age of concrete at the moment considered $t$ and nominal size $h_{0}$, for creep $t=t_{0}$ and for shrinkage $t=t_{s}$. Additionally, in the estimation of shrinkage strain, the coefficient $k_{\mu}$ may be used to take into consideration the amount of reinforcement $A_{s}$ and prestressing $A_{p}$.

\section{Creep and Shrinkage in Eurocode 2 (EC2)}

Eurocode 2 (EN 1992-1-1) describes two methods for the estimation of creep and shrinkage. A simplified method may be adapted when great accuracy in the estimation of time-dependent deformations is not required. Thus, the final creep coefficient may be extrapolated from graphs for different strength classes of concrete, different humidity, nominal sizes and types of cements. In EC2-1-1 [2], Annex B basic equations for determining creep coefficients and drying shrinkage strain development over time are presented. These should be used for numerical calculations when a development over time is required. The equations use the mean compressive strength $f_{c m}$ instead of the concrete class. The other initial parameters are the same like in the Polish code, i.e., ambient humidity, notional size, class of cement, time of loading or time of commencement of the drying shrinkage.

\section{Comparison of Codes for Creep and Shrinkage}

The codes, like many concrete standards and design guides, classify concrete according to its compressive 
strength. Concrete mixtures parameters are considerably influencing the proprieties of hardened concrete. However, it is not possible to use all the concrete mix parameters in the design codes. In Eurocode 2, concrete strength is used as an adequate parameter to describe concrete mixtures and deformability parameters, as is not in the Polish code.

A comparison of creep and shrinkage of concrete over time was performed according to the Polish

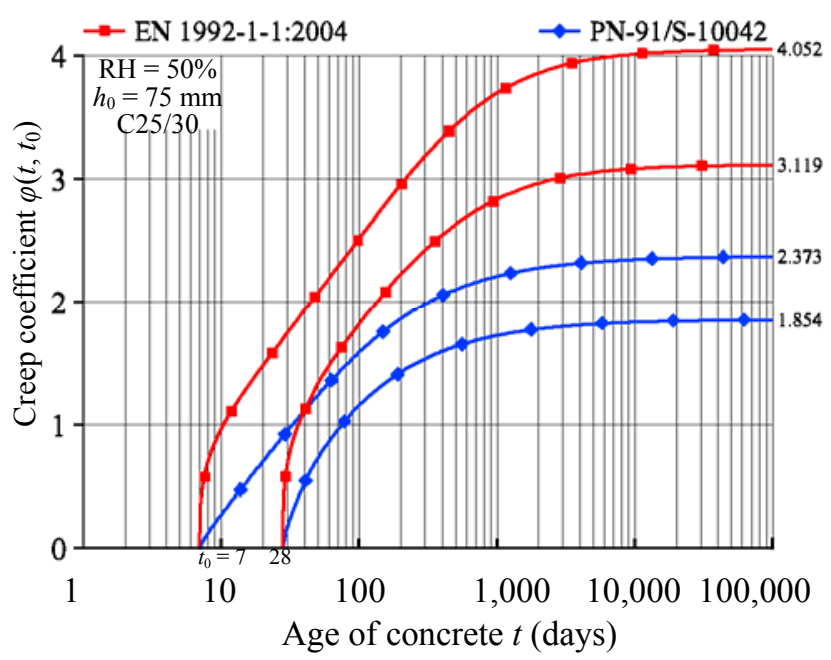

(a)
Bridge Standard and Eurocode 2 for humidity $\mathrm{RH}=$ $50 \%$ and $80 \%$, the age of concrete at loading $t_{0}=7$ days and 28 days and C25/30 strength class of concrete. For comparison of creep deformation versus time, the creep coefficients (Fig. 1) and creep functions (Fig. 2) are employed. In both comparisons, creep values are much higher for Eurocode 2. The shrinkage strains are compared in Fig. 3 for the same concrete and environmental parameters and at the time

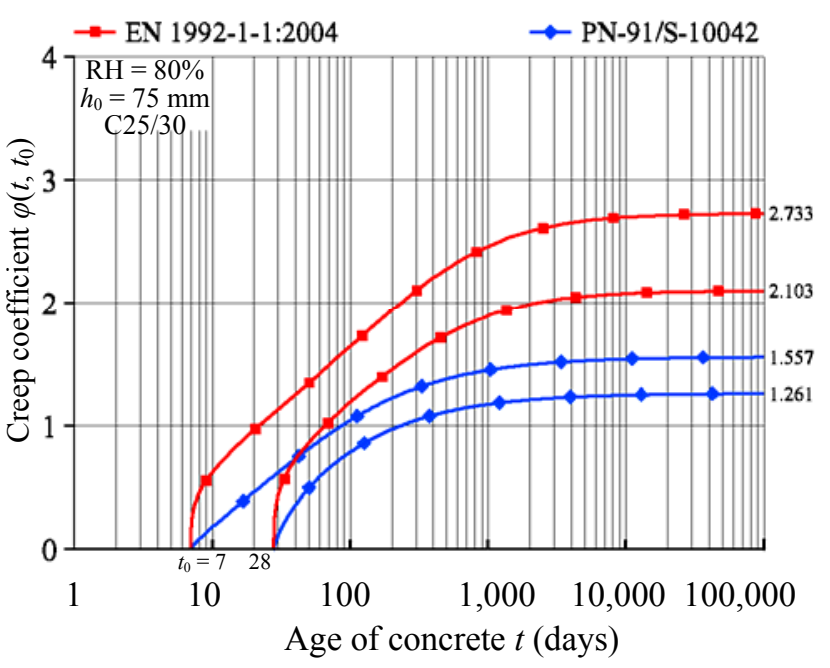

(b)

Fig. 1 Creep coefficients $\varphi\left(t, t_{0}\right)$ for the age of loading $t_{0}=7$ days and 28 days, at relative humidity: (a) $R H=50 \%$; (b) $R H=$ $80 \%$.

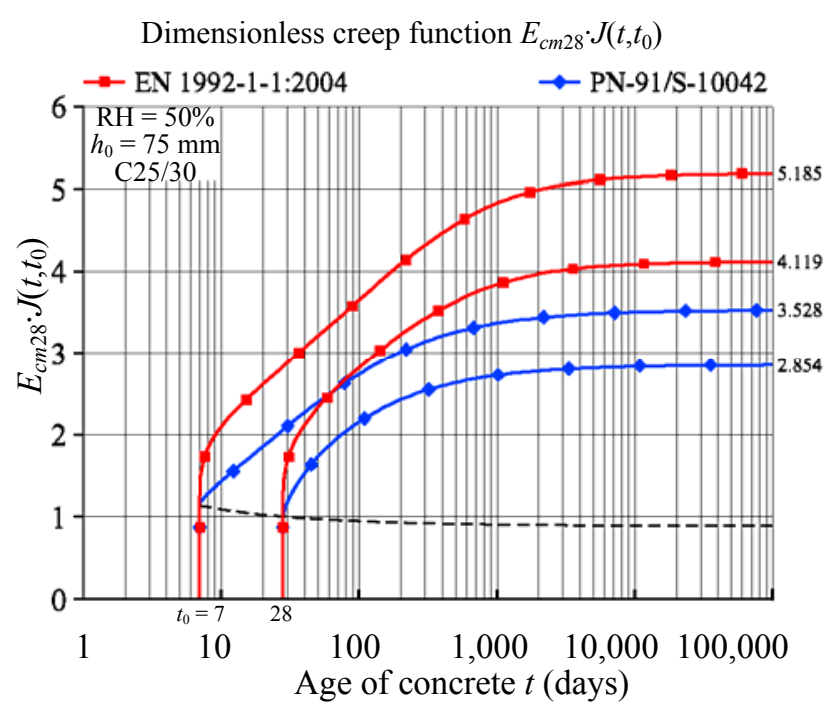

(a)

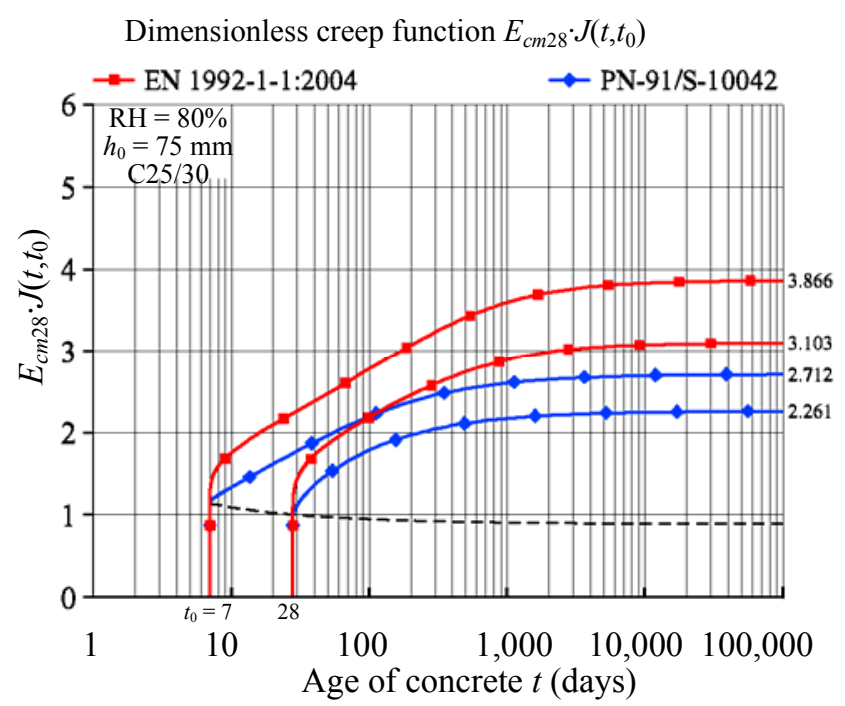

(b)

Fig. 2 Creep functions for the age of loading $t_{0}=7$ days and 28 days, at relative humidity: (a) $R H=50 \%$; (b) $R H=80 \%$. 


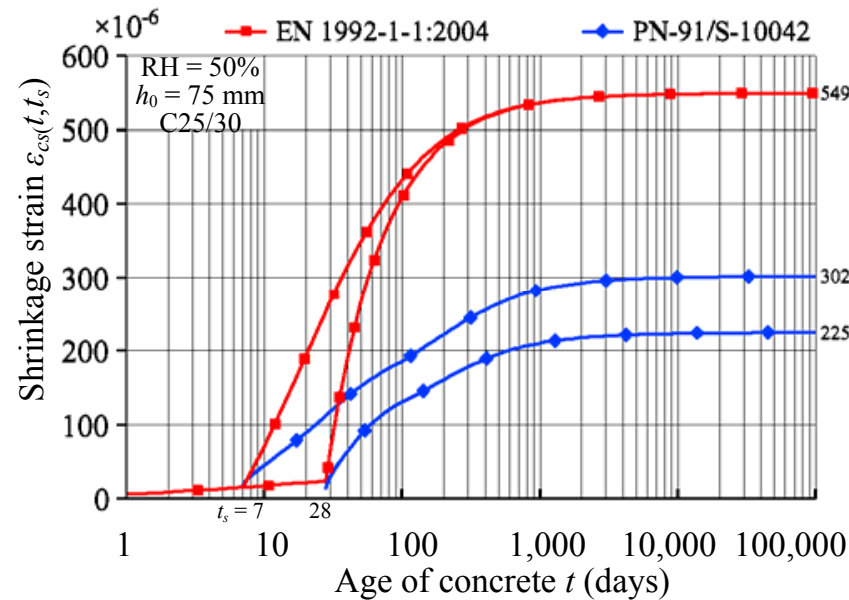

(a)

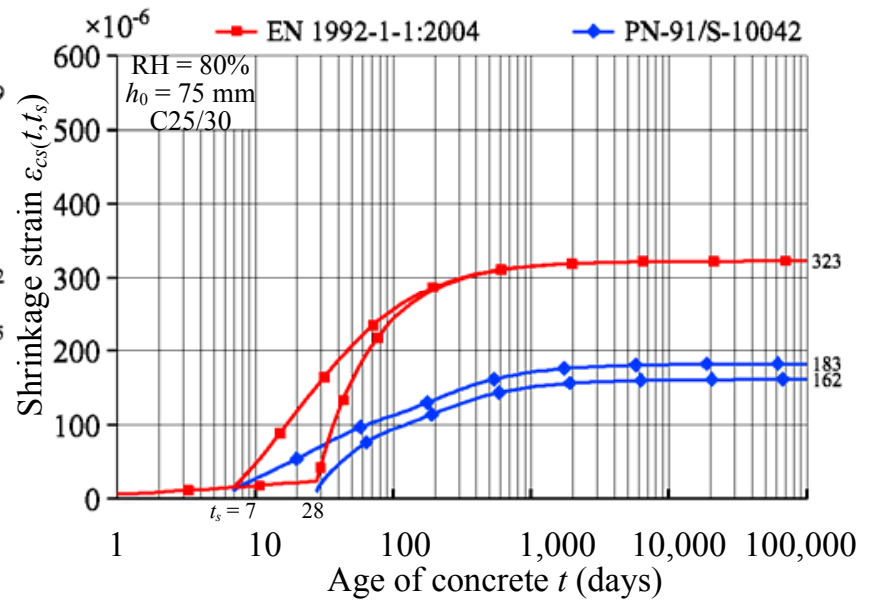

(b)

Fig. 3 Shrinkage strains $\varepsilon_{c s}\left(t, t_{s}\right)$ for the age of the start of drying $t_{s}=7$ days and 28 days, at relative humidity: (a) $R H=$ $50 \%$; (b) RH $=80 \%$.

Table 1 Final shrinkage strains $\varepsilon_{c s, \infty} \times 10^{6}$ for ordinary concrete according to PN-S and EC2.

\begin{tabular}{|c|c|c|c|c|c|c|c|c|}
\hline \multirow{4}{*}{$\begin{array}{l}\text { Age of concrete at } \\
\text { the end of moist } \\
\text { curing } \\
t_{s} \text { (day) }\end{array}$} & \multicolumn{8}{|c|}{ Notional size $h_{0}(\mathrm{~mm})$} \\
\hline & \multicolumn{4}{|c|}{ Relative humidity, $\mathrm{RH}=50 \%$} & \multicolumn{4}{|c|}{ Relative humidity, $\mathrm{RH}=80 \%$} \\
\hline & \multicolumn{2}{|c|}{150} & \multicolumn{2}{|c|}{600} & \multicolumn{2}{|c|}{150} & \multicolumn{2}{|c|}{600} \\
\hline & PN-S & $\mathrm{EC} 2$ & $\overline{\mathrm{PN}-\mathrm{S}}$ & $\mathrm{EC} 2$ & $\overline{\mathrm{PN}-\mathrm{S}}$ & EC2 & $\overline{\mathrm{PN}-\mathrm{S}}$ & $\mathrm{EC} 2$ \\
\hline 7 & 430 & & 310 & & 260 & & 210 & \\
\hline 28 & 320 & 511 & 300 & 396 & 230 & 302 & 210 & 237 \\
\hline 90 & 190 & & 280 & & 160 & & 200 & \\
\hline
\end{tabular}

Table 2 Final creep coefficients $\varphi\left(\infty, t_{0}\right)$ for ordinary concrete according to PN-S and EC2.

\begin{tabular}{|c|c|c|c|c|c|c|c|c|}
\hline \multirow{4}{*}{$\begin{array}{l}\text { Age of concrete } \\
\text { at loading } \\
t_{0} \text { (days) }\end{array}$} & \multicolumn{8}{|c|}{ Notional size $h_{0}(\mathrm{~mm})$} \\
\hline & \multicolumn{4}{|c|}{ Relative humidity, $\mathrm{RH}=50 \%$} & \multicolumn{4}{|c|}{ Relative humidity, $\mathrm{RH}=80 \%$} \\
\hline & \multicolumn{2}{|c|}{150} & \multicolumn{2}{|r|}{600} & \multicolumn{2}{|c|}{150} & \multicolumn{2}{|c|}{600} \\
\hline & $\mathrm{PN}-\mathrm{S}$ & $\mathrm{EC} 2$ & $\mathrm{PN}-\mathrm{S}$ & $\mathrm{EC} 2$ & $\mathrm{PN}-\mathrm{S}$ & $\mathrm{EC} 2$ & $\mathrm{PN}-\mathrm{S}$ & $\mathrm{EC} 2$ \\
\hline 7 & 3.2 & 3.60 & 2.5 & 2.96 & 2.1 & 2.55 & 1.9 & 2.30 \\
\hline 28 & 2.5 & 2.77 & 2.0 & 2.28 & 1.7 & 1.97 & 1.5 & 1.77 \\
\hline 90 & 2.1 & 2.22 & 1.6 & 1.82 & 1.4 & 1.57 & 1.2 & 1.41 \\
\hline
\end{tabular}

of the start of drying $t_{s}=7$ days and 28 days. It is characteristic for the shrinkage strain estimated according to Eurocode 2 that its final value does not depend on the time of the start of drying (Table 1). The shrinkage values are also much higher for Eurocode 2. As for normal strength concrete, the magnitude of autogenous shrinkage is of a small value in Eurocode 2 and it is neglected in the Polish Bridge Standard.

The final creep coefficients $\varphi\left(\infty, t_{0}\right)$ for the Polish Bridge Code (PN-S) and Eurocode 2 are compared in
Table 2 and the final shrinkage strains $\varepsilon_{c s, \infty}$ are compared in Table 1. The final values are estimated for concrete at 70 years as in Eurocode 2. The standard ranges of relative humidity and notional sizes are taken from the Polish Bridge Code. As the Polish Bridge Standard does not take into account a concrete strength and a type of cement in calculation of time-dependent deformations, the concrete of grade $\mathrm{C} 25 / 30$ was used for the comparison, as a standard material.

For all the ranges of humidity and notional sizes 
calculated, the Polish Bridge Standard gives much lower values of creep and shrinkage. However, in both code models, creep and shrinkage approach their final values (horizontal curves).

Design lower values of time-dependent deformations may lead to serviceability or durability failures as that increased prestressed losses, deflection, induced cracking and shortening of members [10]. The underestimation of the deformational parameters in modern bridge concretes currently under construction in Poland in great numbers means unrealistic designs for serviceability, cracking and deformations. The majority of new concrete bridges are prestressed concrete structures which are highly prone to time-dependent effects. Current concrete technologies for a large-span bridge construction tend to employ continuous pours and use of cements with higher early strengths and shorter striking times. A large range of additives and chemical admixtures for concretes are available on the market and are successfully applied in concrete mixtures for improving concrete quality and avoiding unexpected problems during construction in different ambient conditions. However, some admixtures, if not all, have chemistry that affects the properties of concrete. The presence of one admixture usually affects the performance of another. These expected changes in concrete performance are much better covered by Eurocode rules which are adjusted to current concretes and cements.

\section{Conclusions}

The basic parameters for estimating creep and shrinkage in concrete according to the Polish Bridge Standard and Eurocode 2 are presented. The Polish Bridge Standard gives a highly simplified description of the time-dependent deformation of concrete in the form of final values for creep coefficients and shrinkage strains for ordinary concrete under typical construction conditions. Such a simplified procedure allows for the easy calculation of final values for creep and shrinkage strains in simple reinforced or prestressed concrete structures which in the main had been used for bridge structures. The values are given only for ordinary concrete in normal technological conditions. The introduction of higher strengths of concrete in bridge engineering, the development of prestressed concrete structures and sophisticated methods for concrete bridge construction also require more accurate analyses taking into account the actual time-dependent behavior of concrete. In Eurocode 2 $[2,3]$, along with simplified rules for estimating the final values of creep and shrinkage, more accurate methods are given. For bridge structures, in special cases, the estimation of time-dependent properties on short-term testing is recommended in EC2-2 (for bridges) [3]. EC2-2 also gives basic recommendations for the rheological analyses of time-dependent effects and their applications to concrete bridge structures.

Direct comparison of creep and shrinkage in concrete according to the Polish Bridge Code and Eurocode 2 is difficult because of various initial parameters and different accuracy. Approximate estimation for creep and shrinkage in concrete for ordinary concrete with a typical concrete mixture is presented in the paper. The final creep coefficient values along with shrinkage strains are compared. Changes in their values versus time are presented. Time dependent creep functions versus time are also compared. Generally, Eurocode 2 gives higher values for creep and shrinkage in concrete but simultaneously it introduces more accurate procedures for the estimation of creep and shrinkage. These allow for a more rational prediction of the time-dependent behavior of concrete and concrete bridges so that these structures could be more durable and safer.

\section{References}

[1] Polish Standard Institution. 1992. PN-91/S-10042. Bridges. Concrete, Reinforced Concrete and Prestressed Concrete Structures. Warsaw: Polish Standard Institution. (in Polish)

[2] European Committee for Standardization. 2004. EN 1992-1-1, Eurocode 2: Design of Concrete Structures. 
Part 1-1: Generals Rules and Rules for Buildings. Brussels: European Committee for Standardization.

[3] European Committee for Standardization. 2008. EN 1992-2, Eurocode 2: Design of Concrete Structures. Part 2: Concrete Bridges-Design and Detailing Rules. Brussels: European Committee for Standardization.

[4] ACI (American Concrete Institute) Committee. 2009. "ACI 209.2R-08, Guide for Modeling and Calculating Shrinkage and Creep in Hardened Concrete." In $A C I$ Manual of Concrete Practice, edited by Bischof, C. R. Farmington Hills: ACI.

[5] Al-Manaseer, A., and Masood, H. 2009. "Sensitivity of Models for Predicting Creep of Concrete." In Proceedings of Eighth International Conference on Creep, Shrinkage and Durability Mechanics of Concrete and Concrete Structures, 1385-96.

[6] Biliszczuk, J., and Hołowaty, J. 2010. "After the Collapse of a Bridge with Record-Braking Span.” Inżynieria $i$ Budownictwo (Building Engineering) 9: 489-3. (in Polish)

[7] Fanourakis, G. C., and Ballim, Y. 2006. “An Assessment of the Accuracy of Nine Design Models for Predicting Creep in Concrete." Journal of the South African Institution of Civil Engineering 48 (4): 2-8.

[8] Ghali, A., Favre, R., and Elbadry, M. 2012. Concrete Structures: Stresses and Deformations: Analysis and Design for Serviceability. London and New York: Spon Press.

[9] Gilbert, R. I., and Ranzi, G. 2011. Time-Dependent Behaviour of Concrete Structures. London and New York: Spon Press.

[10] Hołowaty, J. 2015. "Conventional Models for Creep in Normal- and High-Strength Concrete." Architecture, Civil Engineering, Environment. (in press)

[11] Bažant, Z. P., Li, G. H., and Yu, Q. 2009. "Prediction of Creep and Shrinkage and Their Effects in Concrete Structures: Critical Appraisal." In Proceedings of Eighth International Conference on Creep, Shrinkage and Durability Mechanics of Concrete and Concrete Structures, 1275-89.
[12] Radomski, W. 2012. "Some Remarks about Creep Effects in Concrete Bridge Structures.” Presented at Conference: Prestressed Concrete Structures, Cracow. (in Polish)

[13] Hołowaty, J. 2003. "Creep of Concrete in Polish Codes." In Proceedings of 8th Seminar: Contemporary Methods of Bridge Strengthening and Rebuilding, 125-31. (in Polish)

[14] Hołowaty, J. 2012. "Creep of Concrete in the Bridge Code and Eurocode 2." In Proceedings of 6th Bridge Conference: Construction and Accessories of Bridges, 77-86. (in Polish)

[15] Hołowaty, J. 2012. "Contemporary Models for Creep in Cement Concrete." In Proceedings of Conference: Concrete Days: Tradition and Novelity, 901-10. (in Polish)

[16] Flaga, K. 2006. "Properties of Concrete According to Eurocode 2-2004." In Basic Design of Reinforced and Prestressed Concrete Structures According to Eurocode 2, edited by Knauff, M. Wrocław: Lower Silesian Publishing. (in Polish)

[17] Hołowaty, J. 2013. "Comparison of Creep in Concrete Formulated in the Bridge Codes and Eurocode 2." Inżynieria i Budownictwo 9: 338-42. (in Polish)

[18] Hołowaty, J. 2013. "Comparison of Eurocode 2 and Polish Bridge Standards for Creep and Shrinkage of Concrete-Necessity for Implementation.” In Proceedings of the 9th Central European Conference on Concrete Engineering CCC 2013: Concrete Structures in Urban Areas, 76-9.

[19] Hołowaty, J. 2014. "Contemporary Models for Shrinkage in Cement Concrete." In Proceedings of the 10th Central European Conference on Concrete Engineering CCC 2014: Concrete Offers for Period of Economic Recovery. (in press)

[20] ACI (American Concrete Institute) Committee. 2009. "ACI 209.2R-92 (Reapproved 2008), Prediction of Creep, Shrinkage and Temperature Effects in Concrete Structures." In ACI Manual of Concrete Practice, edited by Bischof, C. R. Farmington Hills: ACI. 